\section{Revue de Sémantique et Pragmatique}

41-42 | 2017

Cadrage sur la variation, le changement lexical et le changement grammatical en français actuel

\title{
Percepteur des postes ou Operational Platform Manager : quelles significations sont « cachées » derrière les usages linguistiques des professionnels de Bpost?
}

\section{Sophie Collonval}

\section{(2) OpenEdition \\ Journals}

Édition électronique

URL : http://journals.openedition.org/rsp/466

DOI : $10.4000 /$ rsp.466

ISSN : $2610-4377$

Éditeur

Presses universitaires d'Orléans

Édition imprimée

Date de publication : 1 décembre 2017

Pagination : $99-113$

ISSN : 1285-4093

Référence électronique

Sophie Collonval, «Percepteur des postes ou Operational Platform Manager : quelles significations sont « cachées » derrière les usages linguistiques des professionnels de Bpost? », Revue de

Sémantique et Pragmatique [En ligne], 41-42 | 2017, mis en ligne le 01 décembre 2018, consulté le 21 avril 2019. URL : http://journals.openedition.org/rsp/466 ; DOI : 10.4000/rsp.466 


\section{Percepteur des postes OU Operational Platform MANAGER : QUELLES SIGNIFICATIONS SONT « CACHÉES 》 DERRIÈRE LES USAGES LINGUISTIQUES DES PROFESSIONNELS DE BPOST ?}

Sophie Collonval Institut NaLTT (Université de Namur, Belgique)

$\mathrm{t}$ « un produit de l'activité de travail et un facteur de productivité de l'entreprise » (Boutet et Heller 2007 : 314). Les langues rapportent et font vendre (Canut et Duchêne 2011 : 8), mais elles structurent également « le maté

t que tout discours est le produit de contraintes d'ordres multiples (e.a. sociales, psycholinguistiques, physiologiques) » (Hambye iales liées à l'usage d'unités lexicales anglaises alors que leurs 
s langagiers

des professionnels et quelle(s) signification(s) se « cache(nt) » derrière l'usage

épartition territoriale des trois langues officielles, auxquelles peuvent être ajoutés les variétés régionales flamandes, germaniques et wallonnes ainsi que les

ficiels est fixée par les lois de

ois Régions (bruxelloise, flamande et wal

landaise, la région bilingue de Bruxelles-Capitale [français et néerlandais] et la région de langue allemande. 
sont réglés au

reste la liberté linguistique » (Vuye 2010 : 36-37).

ns la vie économique

erlandais) et des langues régionales (picard et flamand) et le parler de

fin de comprendre, plus spécifiquement, l'usage des unités lexicales anglaises ainsi que leurs significations sociales dans un contexte

1.2.1. Enquête dans une implantation postale 
gistrées $(27$ heures

és ou cadres. Les interactions appartiennent à la communication interne : elles sont «

t Westphalen 
rmet pas d'identifier les informateurs parmi 
ociales issues des profils

ifications sociales. Nous postulons que

teur est « gradé », plus il recourt à des termes anglais, surtout s'il travaille dans la sphère financière et commerciale de tte hypothèse en analysant les différences

is cette approche n'est pas une fin en soi.

ues des productions linguistiques et les positionnements

nces en Belgique emploient fréquemment cet idiome ou le 
ls pour la « langue unique » imposée par les responsables au nom du profit ou pour les langues des clients (Lüdi 2011 : 594-

'administrateur délégué annonce que

elle au détri

me « neutre»:

011 : 103-104). En effet,

ans un contexte interna

nt conscients de l'anglicisation entre 
Cet in

nts

Vous arrive-t-il de parler anglais ?».

es ainsi que de l'anglais dans les communications interne et externe de Bpost. 
s noms anglais étant donné la forte présence de cet idiome dans les milieux financier et managérial

$s$ et moins floue que celui de

ion, best, best connection, best in action(s), best 
onction »

s observations. 
iers sélectionnent un idiome « neutre».

En effet, « l'anglais devient, dans certaines situations, une langue coupée de son association à l'identité linguistique » des anglophones (Lamarre et Lamarre 2006 : 66). Ce choix témoigne d'enjeux pragmatiques liés à l'équilibre entre les coûts et les bénéfices (Duchêne 2011 : 103-104), mais pas uniquement. L

ar le mot engage tout un programme d'action », de représentation et d'organisation (Boutet $2016: 108$ ). Ainsi, nous pensons que l'usage d'unités lexicales anglaises illustre des enjeux pragma

un pays communautarisé contribue à l'édification

iser un idiome officiel et de ne pas provoquer de crise 
ofit - voire une

ent d'une logique de hiérarchisation des activités de travail au sein d'espaces de travail socialement stratifiés » (Duchêne

comprendre les significations sociales liées à l'usage des unités lexi 
s coûts de traduction, ouverture

attribuées aux unités lexicales anglaises : celles, «positives », qui peuvent être associées à une identité entrepreneuriale unique, nationalement et mondialement, et celles, «négatives », qui véhiculent l'inadé

rrait faire l'objet d'un futur travail. 
avail », in

ne socio

ibéralisme, inégalités sociales et plurilinguisme. L'exploita du plurilinguisme en entreprise. Une enquête

exploratoire », dans

ye, P. (2012), « Le politique à travers les mots. Pour une approche formelle des discours politiques $»$, in 
cio-politique de la langue française à Bruxelles »,

ionnelle»,

e protection et ouverture linguistique ",

tion des langues nationales européennes », in

, C. e.a. (2006), « Le tourisme patrimonial. La commercialisation de l'identité franco-canadienne et ses enjeux langagiers »,

linguistiques en Belgique dans une perspective histo 